\title{
Operating of special car under the vision of shared economy
}

\author{
Hongchao Ning ${ }^{1, a}$,Tongxin Xue ${ }^{1, b}$ \\ ${ }^{1}$ Harbin University of Commerce,Harbin 150000,China; \\ a734064902@qq.com, b327790421@qq.com
}

Keywords: Sharing economy, special car, legal status.

\begin{abstract}
Actually, special car is a commercial vehicle which is certificated by taxi platform and government. It used to transport passengers, and mainly through mobile phones and other mobile devices to complete the order booking and payment. At present, the mainstream APP of special car in our country, include Didi Chuxing, Yidao Yongche, Ucar and Uber. With the influence of first special car case and other related events, the ministry of transport, drafted a file which name is Internet booking taxi business service management interim measures (draft), in October 2015, and the department published it to the public for soliciting opinions.
\end{abstract}

\section{Introduction}

Shared economy, generally refers to a new economic pattern, whose the main purpose is to obtain a certain reward, and it also based on a stranger world. Moreover, it is a temporarily transfer in the right to use of goods. The essence of this pattern is to integrate offline item, such as idle items, labor, education, medical resources, etc. Actually, this kind of sharing is usually achieved by the network as a medium. special car, in terms of its essence, is a Shared economy that integrate idle resources cars, and it provide travel services on the basis of the public to pay a certain consideration fee, like Didi Chuxing, an application where taxis, premium cars and designated drivers can be hired via mobile phone. However, since the collective strike of Shenyang taxi in January 4, 2015, the taxi industry has already appeared boycott several times to against the activities of the special car. It is no doubt that the emergence of the special car caused a great influence on traditional taxi industry. However, Hegel once said "the existence is reasonable", special car as a model of Shared economic has its necessary and foundation in existence, and it should not be banned. But if we want to realize the value of the special car better, and make social and consumers can get more benefits, we should determine the nature of the special car at first.

\section{Analysis of word meanings about special car}

For a long time, there are a lot of private car drivers who work on paid passenger service, and they earn some pin money by this way. But for the behavior of private car drivers, traffic management department will cite the relevant provisions of the existing road transport management, and classified it as the unlicensed taxi, which have no business certificate for processing. But it is not completely equity between the meaning of the private car and special car. The most obvious description is there exiting a third-party car platform (the nature of the platform are not considered) between the special car drivers and passengers, and the third-party is used to regulate the rights and duties in the relationship between passengers and drivers. In combination with the practical situation of the society, the government and a part of the social public often regard special car as an unlicensed taxi. But in some ways, the operating mode between the special car which operate by private car drivers, unlicensed taxi, taxi, and the special car with employment contract, also exist some similarities and differences.

\subsection{Special car and unlicensed taxi}

Generally speaking, there were two components to affirm the unlicensed taxi: the one is, the driver who has not obtained a road transport business license; the other one is, they must be engaged in 
business transportation behavior. In addition, we also should estimate the social harmfulness for the operation of the unlicensed taxi, which meet extremely serious degree. By the way, the drivers who engaged in unlicensed taxi operating does not have operation qualification, and he doesn't need to pay the part of the money to the car rental company also do not need to pay business tax. The vehicle maintenance condition of unlicensed taxi can't make passengers satisfactory. Because of the driver 's low quality in serve, and the illegal driving behaviors like overload and over-speed occurs frequently, such as the safety of passengers can't get effectively protection. And when they compete with taxi, they will lower prices, as the special period like traffic rush, they will raise the prices malicious, the behavior like this has seriously disrupted social order. However, the special car is provided by private owners themselves, they have various car models which passengers can select. Passengers can select vehicle according to the demand of themselves. And the price will be matched corresponding, because its operation has its definite price specification, both place the order and payment is conducted through the network, the transacting behavior has the third-party to guarantee, the car platform can provide and promise a high degree security for two parties.

Special car is the product of Shared economy, although in the early stage of development, it did not have operating harmful to the society like unlicensed taxi inherent. Therefore, there have essential differences between special car and unlicensed taxi.

\subsection{Special car and taxi}

The biggest difference between special car and Taxi is whether there exists any relevant specifications and legal system or not. The operations of Taxi are managed by the law of the People's Republic of China on road transport regulations. And because of the lag of the law, special car as a new thing, the relevant laws and regulations is still not perfect. But in view of the shortcomings of taxi industry, such as administrative monopoly, poor service attitude, as well as the economic development, special car as a kind of type which can reflect the properties of Shared economy, is inevitable in travel industry. History is always amazing similar, as early as the car appeared, carriage driver also erupt a massive wave of strikes. Dialectical materialism thinks that conforms to the social process of things will eventually replace the old things, from this point, the appearance of special car can inspire the taxi industry competition consciousness, and provide a better service to consumers.

\subsection{The special car between private car and employment}

Most public know special car is based on private cars. But in the practice, some platform such as Ucar, does not allow private cars to join. Its operation mode is own driver and their own vehicles, the relationship between platforms and driver is based on the contract of employment. This is also the biggest difference between private car and employment car. Based on this kind of relations, in terms of responsibility, employment car platforms will take their workers vicarious liability without fault. And the doctrine about the relationship between the private car driver and car platforms are have the following, such as labor relations, brokerage contract. Under the corresponding each point of view, for disputes which in the process of operation between the private car owners and customers, it is not clear about the platform whether to take responsibility, and the how to take responsibility. Didi was announced to the public that they will afford for the owner to operate in fine, but it didn't explain about how to bear responsibility in accidents dispute. Step back to speak even if there is this kind of regulation, the platform should also be the responsibility of the fault responsibility, and the responsibility of third-party trading platform may reference the way of Taobao. It means that platform will take fault liability when they not fulfill the duty of reasonable review obligation.

\section{The identification of nature of special car operation}

In the competition between the specific behavior of special car and Taxi industry, some scholar think that the special car have a lot of negative effects. For this reason, we should be regarded it as illegal operations, and thus should be prohibited. It also has a view that operating special car constituted 
unfair competition.

\subsection{Whether the special car constitutes illegal operations}

According to the People's Republic of China on road transport regulations, engaged in the management of road transport, shall obtain the road business license first, otherwise, the road transport management institution(at or above the county level)will punish the violator, according to the circumstances of the behavior. We can know that, the unlawful operation have the following two conditions, namely has not obtained a road transport business license, and engaged in road transport business without authorization. There is no doubt that the behavior of transportation of the special car is commercial. So when we need to judge whether the car constitutes illegal operation, only need to judge the behavior of the car platform which give the car license to the driver, which means when the driver of the special car after applied for car platform and get the license, whether it can be regarded as already obtained road transport business license.

According to the rules, which named the road transport regulations, as long as the taxi driver will get operation qualification when they going through relevant procedures, and in essence this license is based on the affiliated. However, the affiliated need some condition to achieve: 1, there are individual or partnership contributive to buy a vehicle; 2, there is a transport enterprises who have transport operation qualification; 3 , this company agreed the behavior about registered the vehicle in his name; 4 , the vehicle engaged in transport business with the name of the enterprise. However, according to administrative permit law, the article 9, the administrative licensing which obtain in accordance with the law, besides the laws and regulations in accordance with the statutory conditions and procedures may be transferred, shall not be transferred. This article belongs to the mandatory provisions. Obviously, the taxi industry behavior is contrary to this. In addition, the affiliated operating was widespread in the market, and the relevant department didn't handle it as a invalid civil behavior. It is still in a state of uncertainty about the third-part platform which provide special car a affiliated whether has a formal qualifications, the driver of the car is equivalent to have achieved after going through the formalities for the affiliated business license and other issues.

Although the legal regulations is still not perfect, but in practice, some local specification has recognized the qualification of car platform, such as drops fast car platform in October 2015 from the Shanghai municipal committee won the first network permission about car rental business license. It is obvious that the special car is gradually accepted by legal process.

\subsection{Whether the special car constitutes unfair competition}

The market economy encourage the fair competition and prohibit unfair competition. In practice, the taxi industry regard the special car as an unfair competition and resist it. But to judge a behavior whether belong to acts of unfair competition, we need judge it with the general constitutive requirements of acts of unfair competition. The requirement of unfair competition has the following five: the subject qualification comply with the rules of law; There exit a behavior about the acts of unfair competition in objective; Damage to the rights and interests; A causal relationship between loss and acts of unfair competition; Subjective fault.

Combining with the above, the special car is not unlawful operation, and the affiliated qualification of car platform has also been gradually in the process of legal. Therefore, the dispute whether the special car constitutes illegal competition should be attribute to, whether the special car driver and car platform put into effect to acts of unfair competition objectively. Specifically, first of all, in the relevant market competition often need to or more than two operators, but also require them consciously through various means and methods to carry out the competition and compete for customers. Second, the affirm "improper". Distinguished with competition, the recognition of improper has great subjective, usually need to combined with the specific case of the judge. 
China's anti-unfair competition law, in the second chapter, define specific acts of unfair competition, including: confusion behavior, compulsory transaction behavior, compulsory administrative management behavior, commercial bribery, false propaganda behavior, the behavior violate business secret, low-priced dumping behavior of infringing business secret, tying unreasonable and the additional terms, unfair sweepstakes, vilified goodwill behavior, collusion behavior in the tendering and bidding etc. But in the operation of special car does not exist this behavior, and the car platform operation was conducted in accordance with the relevant laws and regulations, also belong to the legal state.

Specifically, car platform is to integrate the vehicle idle resources, centralized traffic control, and uses the $\mathrm{O} 2 \mathrm{O}$ model connects passengers and the driver of the network trading platform, it does not exist the acts of unfair competition. In the field of private law, to the public, the method does not prohibit the freedom, since there is no unfair competition among the special car operate, it belongs to the legitimate competition behavior.

From the market economy, the special car have comfort riding circumstance and convenient online payment, this also is superior to the taxi service, and the emergence of the special car fill the gap of city travel insufficient supply ability and lower service level. But in terms of current status, industry management department of car platform management system lags behind, although industry market competition is intense but there is no relevant specification. So that the special car which conformed the original shared economic trend was impeded and the shocked the taxi market, thus the special car rejected by the taxi industry again and again.

Therefore, the special car does not belong to illegal business and unfair competition. It's an industry which impact by Shared economic and comes from the spontaneous of market.

\section{Summary}

The inherent disadvantages of taxi industry, such as administrative monopoly, high part of the money, poor service attitude, encouraged special car industry to a good development. In a sense, the appearance of the special car industry is a kind of incentive mechanism, which is social spontaneous, so as to promote the taxi industry to improve their service level. Last October the first network license about car rental platform has opened the door of legalization of special car rental industry, this year on July 28, joint of the ministry of public security ministry of transport and other seven released on the basis of the opinions from all sides of the Internet booking taxi business service management interim measures. As a beginning, there will be more and more accord with qualification of legally recognized car platforms, and under the condition of market economy and other various promotion, the corresponding specification of network lease car also will be more and more perfect, to match the operation mode of the social economy more and more.

\section{References}

[1] Shaogang Lv, Shaojun Zhu . Reporters and secretly Internet car platform - How a car into a car [N]. People's Daily. 2015-5-5 (015 edition)

[2] Haifeng tian, Xihai Deng. "The first case about special car "the legal problems and reflection [J]. Journal of southeast university (philosophy and social sciences edition), 2015 (17) : 116-118

[3] Qingli Tang.The regulation path about special car in sharing economic [J]. Journal of Chinese jurisprudence. 2015 (4) 